\title{
Testosterone accelerates the onset of photorefractoriness in baya weaver Ploceus philippinus
}

\author{
N. G. Nair \\ Department of Zoology HNB Garhwal University Srinagar, Reproductive and Wildlife Biology Unit, \\ Garhwal 246 174, India
}

Received: September 6, 2000

Accepted: February 5, 2001

The baya weaver Ploceus philippinus, despite its purely tropical origin and tropical/subtropical distribution, exhibits all features of a typically photoperiodic species. The onset of reproduction in this species is triggered by increasing daylength and breeding is terminated by the development of distinct photorefractory phase. In order to ascertain the involvement of androgens in the development of photorefractoriness the long day response of birds was tested after a prior exposure to varied doses of testosterone. Testosterone treatment accelerated the onset of photorefractoriness as judged from the gonadal status, LH-dependent yellow plumage and testosterone-dependent beak pigmentation. While gonadal development and yellow plumage occurred in the control birds due to the stimulatory long photoperiod, the testosterone administered birds failed to show such developments.

These findings indicate that testosterone might impair the higher photoresponding mechanisms resulting in the development of photorefractoriness.

Keywords: photorefractoriness, Ploceus philippinus, gonadal development, testosterone, photoperiod, reproduction, androgens, birds

The baya weaver Ploceus philippinus is a photoperiodic species $(18,19,20)$. The annual cycle of daylength has been shown to be a potential source of predictive information for the control of reproductive systems in these birds. From the seasonal

Correspondence should be addressed to

N. Gopukumar Nair

Department of Animal Behaviour and Physiology

School of Biological Sciences

Madurai Kamaraj University

Madurai 625 021, India

Fax: 0452859116

E-mail: gopukumar99@usa.net 
studies of gonads, accessory and secondary sex characters and circulating reproductive hormones in captive as well as in free living baya, it became apparent that, although a monsoon breeder, physiological preparation for breeding in this bird commences much earlier in spring. The behavioural parameters like nuptial song delivery and courtship attempts also begin, albeit low key, in April long before the onset of monsoon (6). During the breeding season the male bird wears bright yellow nuptial feathers around its neck, head and on the breast. Beak pigmentation also occurs during this period. The yellow plumage is LH-dependent (21) and beak pigmentation is testosterone dependent (16). During the non-breeding season, the male and female look alike wearing henny plumage and straw colour beak. Breeding is terminated by the development of a distinct photorefractory phase $(2,4)$. This phase signals a total loss of response to the stimulatory photoperiod. Since it is a monsoon breeder the reproductive cycle occurs only after monsoon shower which is irregular or delayed. But, irrespective of monsoon, the onset of photorefractoriness commences with summer solstice. Therefore, remaining in the breeding phase for a relatively longer period will help the birds to coincide the overt activities (supplanting pecks, male-female courtship chases and mounting attempts) with rainfall. Earlier studies show that photorefractoriness in baya sets in after the gonads reach maximum size in June and it progresses gradually with the birds first becoming relative refractory (loss of response to daylength equal to or shorter than those to which previously exposed) in July followed by complete refractoriness (a complete loss of response to photoperiod irrespective of its length) by September $(2,3)$. Does the existence of a relative refractory phase preceding an absolute refractory phase helps the bird to remain in the breeding phase for a relatively longer period? Furthermore, the underlying physiological mechanism of relative refractoriness is also poorly understood. Various hormones like prolactin $(12,13)$, gonadal hormones $(22$, 15 ) and thyroid hormone (10) have been suspected to be involved in the development of refractoriness in birds. Recent studies in European starlings suggest that thyroxine acts as a permissive factor rather than actively driving the photorefractory phase (1). In the baya weaver preliminary studies effected by castration provided indirect evidence for the involvement of testosterone in the development of photorefractoriness (15). As to studies on the hormone profile, testosterone levels in this bird remain high until the last week of August, returned to the normal reproductive cycle. It is hypothesized that the continued exposure to high titres of testicular hormones arising from photostimulation may render the higher photoresponding mechanism less photosensitive. In the present paper, we checked this hypothesis by exogenously administering testosterone during the relative refractory phase and tried to find the postponement/advancement of the photorefractory phase. 


\section{Materials and Methods}

Adult male baya weaver, $P$. philippinus was used in the study. Wild caught birds were released in to the aviary for two weeks for acclimatization. From these birds, adult male birds were separated during the breeding season (April to July) on the basis of yellow plumage and black bill colour from the stock in the aviary. The experiment commenced in July when the birds had attained "relative" refractory phase.

Seventy-five birds were selected and divided into three groups of 25 birds each. Before the start of the experiment observations were made on the reproductive parameters i.e. testicular size plumage colour and beak pigmentation in July. Testosterone propionate (Aquavirone, Nicholas laboratories India Ltd.) was administered intraperitoneally. We chose these doses from a wide range of doses of testosterone we tried earlier to distinguish the inhibitory effects on testosterone on the hypothalamo/hypophyseal system from the direct stimulatory effects on the testes. Each bird of the first and second group was administered $0.15 \mathrm{mg}$ and $0.07 \mathrm{mg}$ testosterone, respectively. $0.15 \mathrm{mg}$ testosterone was injected to the birds over a period of 15 days by injecting $0.01 \mathrm{mg}$ testosterone per day. Similarly $0.07 \mathrm{mg}$ testosterone was injected over a period of 7 days by injecting $0.01 \mathrm{mg}$ testosterone per day. The third group was maintained as the control and received saline only. Development of LH-dependent yellow plumage on left breast was recorded every month after successive depluming. In the first week of August, after the withdrawal of testosterone injections, the testicular size was measured in situ by laparotomy in all the birds and the birds were shifted to long photoperiods (16L:08D). After the transfer to the long photoperiod the gonadal volume of all birds were checked for three consecutive months. Gonadal volume was calculated by using the formula $4 / 3 \pi \mathrm{ab}^{2}$ (where $\mathrm{a}=$ half of long axis and $\mathrm{b}=$ half of short axis of testis). For laparotomy birds were anesthetized during surgery and the long (a) and short (b) axes of left testis was measured and the testicular volume was calculated. During the entire course of this study all the birds were provided with paddy grains (Oryza sativa) and water ad libitum.

\section{Results}

The testicular volume of all the birds of groups I, II and the control birds measured before the start of the experiment (i.e. July) were found to be in the regressive phase. Similarly, before transferring the birds to long photoperiod in August the testicular volume was checked and are found to be still in the regressive phase. On transfer to $16 \mathrm{~L}: 08 \mathrm{D}$, control birds developed testes within a month and regenerated LHdependent yellow nuptial feathers. In addition, the growth after partial development 
showed significant characteristic decline due to development of photorefractoriness $(\mathrm{p}<0.001$, Sep Vs Nov). The testosterone treated groups I and II, which received $0.15 \mathrm{mg}$ and $0.07 \mathrm{mg}$ testosterone respectively, did not show any response in terms of development of gonads and regeneration of feathers and beak pigmentation to stimulatory long day lengths (Fig. 1 and Table I). The degree of response to long photoperiod by birds which received $0.07 \mathrm{mg}$ testosterone was significantly less as compared to that in control birds $(\mathrm{P}<0.001$, Sep Vs Nov).

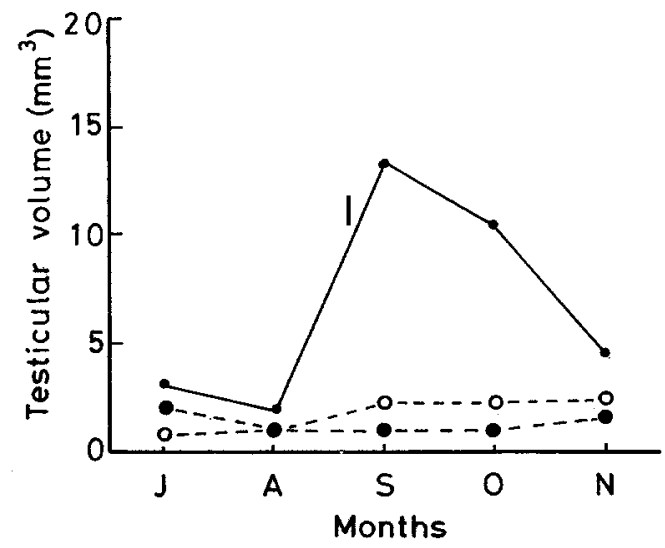

Fig. 1. Effect of different doses of testosterone propionate on the testicular volume of male baya weaver Ploceus philippinus. Mean with S.E. values are given. Where S.E. is not given, the value is insignificant.

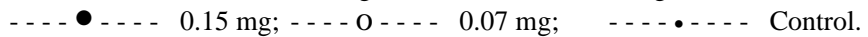

Table I

Effect of different doses of testosterone propionate on the LH-dependent yellow plumage and beak pigmentation in baya weaver

\begin{tabular}{|c|c|c|c|c|c|}
\hline \multirow{2}{*}{$\begin{array}{c}\text { Testosterone } \\
\text { treatment }\end{array}$} & \multicolumn{5}{|c|}{ Observation on plumage colour and beak pigmentation } \\
\hline & $\begin{array}{l}\text { Initial observation } \\
\text { (July) }\end{array}$ & August & September & October & November \\
\hline \multirow[t]{2}{*}{$0.15 \mathrm{mg}$} & YY & YY & $\mathrm{HH}$ & $\mathrm{HH}$ & $\mathrm{HH}$ \\
\hline & $\mathrm{BB}$ & $\mathrm{BB}$ & SS & SS & SS \\
\hline \multirow[t]{2}{*}{$0.07 \mathrm{mg}$} & YY & YY & $\mathrm{HH}$ & $\mathrm{HH}$ & $\mathrm{HH}$ \\
\hline & BB & $\mathrm{BB}$ & SS & SS & SS \\
\hline \multirow[t]{2}{*}{ Control } & YY & YY & YY & YY & YY \\
\hline & BB & BB & BB & BB & BB \\
\hline
\end{tabular}

YY - Yellow plumage

$\mathrm{HH}$ - Henny plumage

BB - Black beak

SS - Straw beak 


\section{Discussion}

The results of our studies show that testosterone can interfere with the photoresponse during the relative refractory phase. Generally the photoperiodic species attain photorefractoriness through the negative feed back mechanism of testosterone on LH and FSH (15). In baya weaver the gonadal development is initiated in April associated with a slow increase in plasma LH and testosterone levels reaching a peak by May to June. However, a high concentration of testosterone will inhibit GnRH and thus gonadotropin release. In the present study, control birds exhibited stimulatory response when shifted to long days during relative refractory phase as evident from the gonadal development and yellow plumage. This gonadal development, although partial (in the normal course, the gonads attain a maximum size of $40 \mathrm{~mm}^{3}$ ) is subsequently followed by the characteristic decline showing that they had ultimately become photorefractory. The development of gonads in controls can be clearly attributed to the mediation of hypothalamo/hypophyseal system since the birds regenerated the LH dependent yellow feathers. Birds receiving testosterone doses did not show the typical photostimulatory response as seen in control birds. The testosterone doses in these birds were high enough to override the stimulatory effect of the long photoperiod.

Photorefractoriness in baya sets in only after gonads have reached peak development and progresses extremely slowly (over 60 days) so that birds exposed to daylength longer than the longest day experienced in nature are able to restimulate the regressing gonad (14). But by the time gonads have reached complete sexual quiescence birds become absolutely refractory even to LL for about 60-70 days. Photorefractoriness in baya thus exhibits both relative and absolute components as described for high latitude species Fringilla coelebs, Zonotrichia leucophrys and the mid-latitude species Carpodacus mexicanus $(7,8,11)$, but in baya the relative phase culminates in the absolute phase rather than succeeding it and the entire refractory phase is extended over a much longer period (5-6 months) $(2,4,5)$. Castration studies in baya weaver birds with growing and near maximal size testes resulted in LH-dependent yellow plumage (17) indicating that gonadal regression could well be a result of negative feed back. However, castrates in the peak and regressive phase grow dull henny feathers; this suggests that photorefractoriness is not maintained by gonadal feed back. Subsequent measurement of LH confirmed this seasonal variation in castration response. Birds castrated in May (breeding phase) show a drastic increase in LH, which however, gradually declines. Birds castrated in July (regression phase) do not show this drastic rise LH. However, when castrates were transferred to long days (15L:09D; 24L:00D) they grew yellow plumage and plasma LH increase several fold (17) clearly indicating gonadal steroids alter photoresponse. Taken together with the present results that the exogenous administration of testosterone during relative refractory phase 
acclerates the decline in photosensitivity, it seems that the enhanced levels of testosterone during the of period not only serve as a feed back but they also interfere with the higher photoresponding mechanisms $(2,6)$ thereby making the bird absolutely refractory.

Experiments in this direction have been conducted in other passerines like whitethroated sparrow and starlings. White throated sparrows were administered testosterone during a short day exposure to determine the effect of steroids on the termination of the gonadal photorefractory condition (22) which shows that the recovery from the photorefractory condition which normally occurs during exposure to short days can be blocked. Another study indicated that the treatment of refractory starlings with androgens during a period of short day exposure does not prevent recovery of photosensitivity (7). Our studies clearly lend support to Turek's finding that the inhibitory effects of testosterone need not necessarily reflect an impairment of the testicular function as interpreted by Goldsmith and Nicholls (9).

\section{REFERENCES}

1. Bentley, G. E., Goldsmith, A. R., Dawson, A., Glennie, L. M., Talbot, R. T., Sharp, P. J.: Photorefractoriness in European starlings (Sturnus vulgaris) is not dependent upon the long-day induced rise in plasma thyroxine. Gen. Comp. Endocrinol. 107, 428-438 (1997).

2. Bisht, M.: Mechanism(s) involved in the termination of seasonal breeding of weaver bird; D.Phil. thesis; HNB Garhwal University, India (1987).

3. Bisht, M., Chandola-Saklani, A.: Short-day experience is not a pre-requisite for the termination of photorefractoriness in the baya weaver Ploceus philippinus. J. Biosci. 17, 29-33 (1992).

4. Chandola, A., Chakaravorty, K.: Termination of seasonal breeding in the photoperiodic weaver bird. J. Exp. Zool. 222, 169-172 (1982).

5. Chandola-Saklani, A., Lakhera, P., Bisht, M.: Mechanism(s) involved in the termination of seasonal reproduction in low latitude birds. In: International Ornitological Congress, ed. Quellet IH., Ottawa University Press, Ottawa, 1988, pp. 612-625.

6. Chandola-Saklani, A., Sharma, K. K., Bisht, M., Lakhera, P.: Ecophysiology of seasonal reproduction in the tropics: the baya weaver. In: Endocrinology of birds, ed. Wada M, Japan Scientific Society Press, Tokyo, 1990, pp. 207-224.

7. Dolnik, V. R.: Migratsionnoe Systoyanie Ptits. Tzdatesstvo. Nauka, Moscow (1976).

8. Farner, D. S., Donham, R. S., Matt, K. S., Mattocks, Jr. P. W., Moore, M. C., Wingfield, J. C.: In: Avian Endocrinology: Environmental and ecological perspectives. eds. Mikami, S., Homma, K., Wada, M. Japan. Sci. Soc. Press. Tokyo/Springer-Verlag, Berlin, 1983, 149-166.

9. Goldsmith, A. R., Nicholls, T. J.: Recovery of photosensitivity in photorefractory starling is not prevented by testosterone treatment. Gen. Comp. Endocrinol. 56, 210-217 (1984).

10. Goldsmith, A. R., Nicholls, T. J., Plowman, G.: Thyroxine treatment facilitates prolactin secretion and induces a state of photorefractoriness in thyroidectomized starlings. J. Endocrinol. 104, 99-103 (1985).

11. Hamner, W. M.: The photorefractory period of the house finch. Ecology 29, 212-227 (1968).

12. Meier, A. H., Martin, D. D., Macgregor, R.: Temporal synergism of corticosterone and prolactin controlling gonadal growth in sparrows. Science 173, 1240-1242 (1971). 
13. Meier, A. H., Ferrel, B. R.: Avian endocrinology. In: Chemical Zoology, ed. Brush, A. H., Academic Press, New York, 1978, pp. 213-271.

14. Nair, N. G., Chandola-Saklani, A.: Timing of photorefractoriness in the reproductive cycle of tropical baya weaver, Ploceus philippinus. Ind. J. Exp. Biol. 36, 1154-1157 (1998).

15. Pavgi, S., Chandola-Saklani, A.: Role of gonadal feed back in annual reproduction of weaver bird: interaction with photoperiod. Gen. Comp. Endocrinol. 31, 72 (1981).

16. Saxena, R. N., Thapliyal, J. P.: Male hormone and bill pigmentation in baya, Ploceus philippinus (Linn). Science Congress, India, p. 29 (1962).

17. Singh, S., Chandola-Saklani, A.: Seasonal variation in photogonadal response of the tropical weaver bird. Gen. Comp. Endocrinol. 45, 521-526 (1981).

18. Singh, S., Chandola, A.: Photoperiodic control of seasonal reproduction in tropical weaver bird. J. Exp. Zool. 216, 293-298 (1981)

19. Singh, S., Chandola, A.: Seasonal variation in photogonadal response of the tropical weaver bird. Gen. Comp. Endocrinol. 41, 520-526 (1982).

20. Singh, S., Chandola, A.: Photoperiodic time measurement in seasonal reproduction of weaver bird. Gen. Comp. Endocrinol. 48, 521-526 (1983).

21. Thapliyal, J. P., Saxena, R. N.: Plumage control in Indian weaver bird (Ploceus philippinus). Naturwissenschaften 24, 741-742 (1961).

22. Turek, F. W., Wolfson, A., Desjardins, C.: Testosterone treatment blocks the termination of the gonadal photorefractory condition in white throated sparrows maintained on short days. Gen. Comp. Endocrinol. 41, 365-371 (1980). 